\title{
Examination of Potential Virulence Factors of Candida tropicalis Clinical Isolates From Hospitalized Patients
}

\author{
Melyssa Negri • Margarida Martins • \\ Mariana Henriques • Terezinha I. E. Svidzinski • \\ Joana Azeredo • Rosário Oliveira
}

Received: 27 July 2009/Accepted: 3 October 2009/Published online: 23 October 2009

(C) Springer Science+Business Media B.V. 2009

\begin{abstract}
Candida tropicalis has been reported to be one of the Candida species which is most likely to cause bloodstream and urinary tract infections in hospitalized patients. Accordingly, the aim of this study was to characterize the virulence of $C$. tropicalis by assessing antifungal susceptibility and comparing the expression of several virulence factors. This study was conducted with seven isolates of $C$. tropicalis from urine and blood cultures and from central venous catheter. C. tropicalis ATCC 750 was used as reference strain. Yeasts adhered $(2 \mathrm{~h})$ to epithelial cells and silicone and $24 \mathrm{~h}$ biofilm biomass were determined by crystal violet staining. Pseudohyphae formation ability was determined after growth in fetal bovine serum. Enzymes production (hemolysins, proteases, phospholipases) was assessed by halo formation on agar plates. Susceptibility to antifungal agents was determined by E-test. Regarding adhesion, it can be highlighted that $C$. tropicalis strains adhered significantly more to epithelium than to silicone. Furthermore, all
\end{abstract}

M. Negri · M. Martins · M. Henriques ( $\square)$.

J. Azeredo · R. Oliveira

IBB-Institute for Biotechnology and Bioengineering,

Centre of Biological Engineering, Universidade do

Minho, Campus de Gualtar, 4710-057 Braga, Portugal

e-mail: mcrh@deb.uminho.pt

T. I. E. Svidzinski

Teaching and Research in Clinical Analysis Laboratory, Division of Medical Mycology, Universidade Estadual de Maringá, Av. Colombo, 5790, Maringá,

Paraná 87020-900, Brazil
C. tropicalis strains were able to form biofilms and to express total hemolytic activity. However, protease was only produced by two isolates from urine and by the isolates from catheter and blood. Moreover, only one $C$. tropicalis (from catheter) was phospholipase positive. All isolates were susceptible to voriconazole, fluconazole and amphotericin B. Four strains were susceptible-dose dependent to itraconazole and one clinical isolate was found to be resistant.

Keywords Candida tropicalis . Virulence factors . Secretion of enzymes · Biofilm · Adhesion

\section{Introduction}

Fungal hospital infections (FHI) incidence has increased significantly over the last decades. Candida species are the most frequently isolated fungi, corresponding to approximately $80 \%$ of FHI, being the fourth responsible for blood stream infection and the overwhelming majority responsible for urinary tract infections [1-3].

Usually, Candida tropicalis is considered the third Candida species most frequently isolated from urine cultures [4, 5]. Moreover, in a recent epidemiological study conducted in 12 Brazilian medical centers, C. tropicalis was the second most frequent Candida species, accounting for 20-24\% of all candidemias [2, 6]. Additionally, C. tropicalis is often found in patients admitted in intensive care units (ICUs), 
especially in patients with cancer or/and requiring prolonged catheterization, or receiving broad-spectrum antibiotics [2, 4, 6, 7].

Several virulence factors seem to be responsible for C. tropicalis infections, which present high potential for dissemination and mortality [8, 9]. Adhesion to host surfaces (epithelial cells and medical devices), as well as biofilm formation, are considered the first step to initiate Candida infection [10, 11]. Furthermore, secretion of enzymes (proteases and phospholipases), as well as hemolytic activity, are recognized as important factors in tissue invasion [10-14].

Hence, the aim of this study was to assess and compare the expression of different virulence factors (enzymes secretion, adhesion and biofilm formation and pseudohyphae production) by several $C$. tropicalis clinical isolates. Moreover, antifungal susceptibility was also determined in order to deeply characterize the virulence of $C$. tropicalis.

\section{Materials and Methods}

Isolates

This study was conducted with seven isolates of C. tropicalis: five obtained from candiduria, one from candidemia and one from a central venous catheter (CVC) and all were from patients admitted to ICUs at the University Hospital (UH) in Maringá, Paraná, Brazil. C. tropicalis ATCC 750 was used as reference strain.

Isolation and Identification

Yeasts were isolated according to hospital routine methods. To perform hemoculture, one volume of blood was inoculated in 10 volumes of Trypticase Soy Broth (Difco, Detroit, Michigan, EUA) and incubated in the automatic BACTEC (Becton-Dickinson Microbiology Systems, Sparks, MD) system. Urine was spread using a calibrated loop $(10 \mu \mathrm{l})$ on CLED medium agar plates (Difco) and incubated at $37^{\circ} \mathrm{C}$ for $48 \mathrm{~h}$. CVC isolated yeasts underwent a well established technique [15]. Briefly, CVC was rolled on blood agar plates (Difco) and incubated at $35^{\circ} \mathrm{C}$ for $72 \mathrm{~h}$. After yeast growth, they were subcultured in CHROMagar Candida ${ }^{\circledR}$ (CHROMagar, BioMerieux, Paris, France) to assess the purity of the culture and the color of the colonies. From this selective and differential medium, yeasts were identified by three methods: the MicroScan rapid yeast identification panel (Dade Behring Inc, CA, USA), the classical biochemical method [16] and molecular identification.

Candida DNA was extracted using the QIAamp ${ }^{\circledR}$ DNA Mini Kit (QIAGEN, IZASA, Lisboa, Portugal) according to the manufacturer's instructions. DNA content was determined by spectrophotometry readings at $260 \mathrm{~nm}$. Aliquots of $10 \mu \mathrm{l}$ were analyzed by electrophoresis in a $0.8 \%$ agarose (Bio-Rad, Lisboa, Portugal) gel in $1 \times$ TBE buffer (Bio-Rad) and visualized with a UV transilluminator after ethidium bromide (Bio-Rad) staining $(0.5 \mathrm{mg} / \mathrm{ml})$. To assess Candida speciation, a polymerase chain reaction (PCR) method previously described [17] was used. Specific primers for the genomic sequences of DNA topoisomerase II of C. albicans, C. dubliniensis, C. tropicalis (genotypes I and II), C. parapsilosis (genotypes I and II), C. krusei, C. kefyr, C. guilliermondii and $C$. glabrata were used.

\section{Adhesion and Biofilm Formation}

Yeast cells were grown at $37^{\circ} \mathrm{C}, 120 \mathrm{rpm}$ for $18 \mathrm{~h}$ on Sabouraud Dextrose Broth (SDB; Difco) and Phosphate saline buffer (PBS)—washed suspensions of each yeast culture were resuspended in RPMI 1640 (Sigma, Saint Louis, Missouri, USA) to a final concentration of $1.0 \times 10^{7}$ cells $/ \mathrm{ml}$. Then, $3 \mathrm{ml}$ of the suspension was added to each well of a 6 -well plate containing either a confluent layer of TCC-SUP human urinary bladder epithelial cell line (DSMZ-German Collection of Microorganisms and Cell Cultures) or a silicone coupon $(2 \times 2 \mathrm{~cm})$ (Neves e Neves, Trofa, Portugal). All procedures were performed in triplicate and repeated in three separate assays.

\section{Quantification of Adhered Yeast Cells}

After $2 \mathrm{~h}$ of incubation $\left(120 \mathrm{rpm}\right.$, at $\left.37^{\circ} \mathrm{C}\right)$, the wells were washed twice with PBS to remove unattached yeasts. Yeast cells were quantified using the crystal violet $(\mathrm{CV})$ staining method.

\section{Epithelial Cells}

Three milliliters of CV stain (1\%) was added to each well containing the epithelial cells with adherent 
yeasts and allowed to stain for $5 \mathrm{~min}$. Then, the wells were washed three times with PBS. In order to remove the $\mathrm{CV}$ stain from the epithelial cells, $3 \mathrm{ml}$ of ethanol:acetone (1:1) was added to each well and removed immediately. Three milliliter of acetic acid (33\%) was added to each well and the absorbance of the final solution was read at $570 \mathrm{~nm}$ in a microtitre plate reader (Bio-Tek ${ }^{\circledR}$ Synergy HT, IZASA). Wells containing epithelial cells without yeasts were used as controls. The mean absorbance of $\mathrm{CV}$ retained by yeasts was expressed as absorbance per unit of well area.

\section{Silicone}

Candida cells adhered to silicone were quantified according to Henriques et al. [18]. Briefly, the coupons containing adherent yeasts were removed from each well and immersed for 5 min in new well plates containing $3 \mathrm{ml}$ of methanol. After withdrawing the methanol, the coupons were allowed to dry at room temperature. Then, $3 \mathrm{ml}$ of CV (1\%) was added to each well and allowed to stain for $5 \mathrm{~min}$. Coupons were transferred to a new well, washed with ultrapure water and immersed in $3 \mathrm{ml}$ acetic acid (33\%) to dissolve the stain. Coupons without yeasts were used as controls. The absorbance of the obtained solution was read in triplicate in a microtitre plate reader at $570 \mathrm{~nm}$. The final number of cells attached, per coupon unit area, was determined using the mean absorbance and the respective calibration curves, previously established.

\section{Biofilm Biomass Quantification}

After $24 \mathrm{~h}$ of incubation $\left(120 \mathrm{rpm}\right.$, at $\left.37^{\circ} \mathrm{C}\right)$ C. tropicalis biofilm forming ability was assessed on inert materials through quantification of total biomass by $\mathrm{CV}$ staining as described above. Experiments were repeated in 3-5 independent assays.

\section{Pseudohyphae Formation}

Pseudohyphae formation was defined as a cell bearing a rounded outgrowth with a length greater than or equal to the diameter of the parent cell, with a constriction at the base. The percentage of cells in pseudohyphae form, against blastospores, was determined by microscopy counting after $2 \mathrm{~h}$ of cell growth in a liquid medium containing equal volumes of RPMI 1640 (Sigma) and fetal bovine serum (GIBCO, New York, USA). In these experiments, 100 cells per field were examined. Each experiment was conducted in triplicate.

Protease and Phospholipase Secretion

Secretion of proteases and phospholipases was detected by the formation of an opaque halo of degradation around the colonies grown in a specific agar plate, according to Rüchel [19] and Price et al. [20], respectively. An aliquot $(5 \mu \mathrm{l})$ of a $1 \times 10^{8}$ cells $/ \mathrm{ml}$ suspension prepared in distilled water was inoculated on protease agar medium (2\% agar, $1.17 \%$ yeast carbon base, $0.01 \%$ yeast extract and $0.2 \%$ bovine serum albumin) $\mathrm{pH} 5.0$ and on phospholipase agar (2\% agar, $1 \%$ peptone, $2 \%$ glucose, $1 \mathrm{M} \mathrm{NaCl}$, $5 \mathrm{mM} \mathrm{CaCl} 2 \cdot 2 \mathrm{H}_{2} \mathrm{O}$ and $8 \%$ egg yolk) and the Petri dishes were incubated for 7 days at $37^{\circ} \mathrm{C}$. The enzymatic activity $(\mathrm{Pz})$ was determined by the ratio between the colony diameter and the colony diameter plus the halo zone as described by Price et al. [20]. Each experiment was conducted in triplicate.

\section{Hemolytic Activity}

Hemolysin production was evaluated using a modification of the plate assay described by Luo et al. [13]. Fresh cultured colonies of $C$. tropicalis were obtained after being spread on Sabouraud Dextrose Agar (SDA; Difco) (18-24 h). Then, a suspension was prepared in saline solution $(0.9 \% \mathrm{NaCl})$ to reach $10^{8}$ cells $/ \mathrm{ml}$, enumerated using a Neubauer chamber. Ten microliters of this suspension was spot-inoculated on sugar-enriched sheep blood (2\% peptone, $1 \%$ agar, $7 \%$ fresh sheep blood, 3\% glucose) and the plates were incubated at $37^{\circ} \mathrm{C}$. After $48 \mathrm{~h}$ they were classified as absent (no halo), partial, or total (completely transparent halo) hemolytic activity. The assay was conducted in quadruplicate on two separate occasions for each yeast isolate tested. A standard strain, C. albicans ATCC 90028, was used as control in each experiment.

\section{Antifungal Susceptibility Test Methods}

The E-test method was used as recommended by the manufacturer with strips, provided by AB BIODISK 
(Solna, Sweden), having the following concentrations: from 0.002 to $256 \mu \mathrm{g} / \mathrm{ml}$; for fluconazole (FLU) and from 0.002 to $32 \mu \mathrm{g} / \mathrm{ml}$ for itraconazole (ITR), voriconazole (VO) and amphotericin B (AMB). The minimum inhibitory concentrations (MIC) of drugs were determined on RPMI 1640 (Sigma) agar with 2\% glucose. An inoculum suspension was adjusted to a turbidity of 0.5 McFarland standard $\left(1 \times 10^{6}\right.$ to $5 \times 10^{6}$ cells $/ \mathrm{ml}$ ) and was incubated at $37^{\circ} \mathrm{C}$ for $48 \mathrm{~h}$. MICs were read as the lowest concentration at which the border of the elliptical inhibition zone intercepted the scale on the strip. Quality control was performed in accordance with the Clinical and Laboratory Standards Institute (CLSI) document M27-A3 [21], using Candida krusei ATTC 6258 and $C$. parapsilosis ATCC 22019. MIC interpretative criteria was performed according to the CLSI M27-A3 [21]: (a) FLU: MIC $\leq 8 \mu \mathrm{g} / \mathrm{ml}$-susceptible (S); $16<$ MIC $<32 \mu \mathrm{g} / \mathrm{ml}$-susceptible-dose dependent (S-DD) and MIC $\geq 64 \mu \mathrm{g} / \mathrm{ml}$-resistant (R); (b) ITR: MIC $\leq$ $0.125 \mu \mathrm{g} / \mathrm{ml} \longrightarrow \mathrm{S} ; 0.25<\mathrm{MIC}<0.5 \mu \mathrm{g} / \mathrm{ml} \longrightarrow \mathrm{S}-\mathrm{DD}$ and MIC $\geq 1 \mu \mathrm{g} / \mathrm{ml}-\mathrm{R}$; (c) AMB $\mathrm{MIC}>1 \mu \mathrm{g} / \mathrm{ml}-\mathrm{R}$; (d) VO MIC $\geq 1 \mu \mathrm{g} / \mathrm{ml}-\mathrm{S}$; $\leq 2 \mu \mathrm{g} / \mathrm{ml}-\mathrm{R}$.

Statistical Analysis

Results obtained were analyzed using the SPSS (Statistical Package for the Social Sciences) program. One-way ANOVA with the Bonferroni test was used to compare the number of adherent cells of the several strains assayed. All tests were performed with a confidence level of $95 \%$.

\section{Results}

A total of seven C. tropicalis isolates was used in this study: five obtained from urine samples, one from blood samples and one from CVC, all from patients admitted to ICUs at the UH of Maringá, Paraná, Brazil. Additionally, all the methods (MicroScan rapid yeast identification panel, classical biochemical and molecular identification) used had identified C. tropicalis with $100 \%$ concordance (data not shown).

Regarding adhesion ability (Fig. 1), it can be highlighted that all $C$. tropicalis adhered in a significantly greater extent $(P<0.05)$ to epithelial cells than to silicone. Considering the differences among the isolates, it is possible to observe from

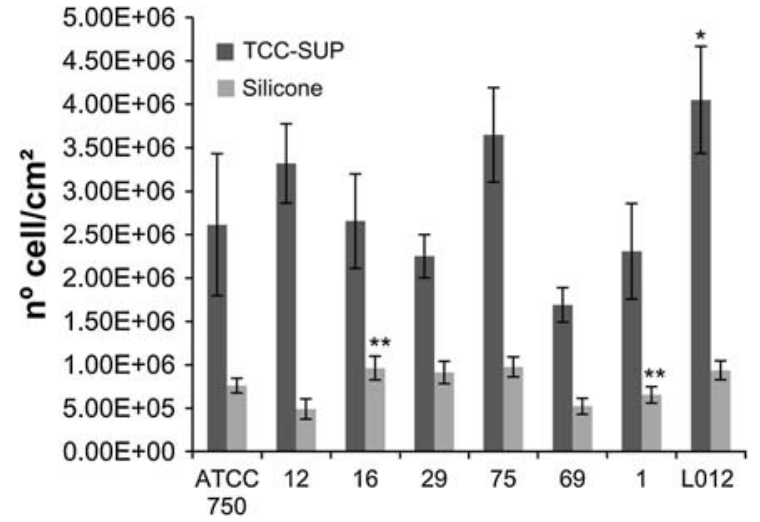

Fig. 1 Number of C. tropicalis cells per $\mathrm{cm}^{2}\left(\mathrm{n}^{\mathrm{o}}\right.$ cell $\left./ \mathrm{cm}^{2}\right)$ (mean \pm standard deviation) adhered to TCC-SUP epithelial cells and to silicone measured by crystal violet staining. * represents the statistical differences $(P<0.05)$ of adhesion extension to TCC-SUP between the strain L012 and strains 1, 16, 29, 69, ATCC 750; ** represents the statistical differences $(P<0.05)$ of adhesion extension to silicone of the strains 16 and 1 compared to the strains 29, 75, L012, ATCC 750

Fig. 1 that $C$. tropicalis L012, from CVC, adhered in a highest extent to epithelial cells $\left(4.05 \times 10^{6}\right.$ cells $\left./ \mathrm{cm}^{2}\right)$ with $P<0.001$ vs. strains $1,16,29,69$ and to silicone $\left(9.37 \times 10^{5}\right.$ cells $\left./ \mathrm{cm}^{2}\right)$ with $P<0.001$ vs. strains 1, 12, 69. Clinical isolates 29 and 69, from urine cultures, adhered to epithelial cells in lower number than other yeasts $(P<0.05$ vs. L012) and the latter, as well as strain 12 , adhered in lower extent than other yeasts to silicone (Fig. 1).

As it can be observed in Fig. 2, all C. tropicalis were able to form biofilms and strains did not present significant statistical differences.

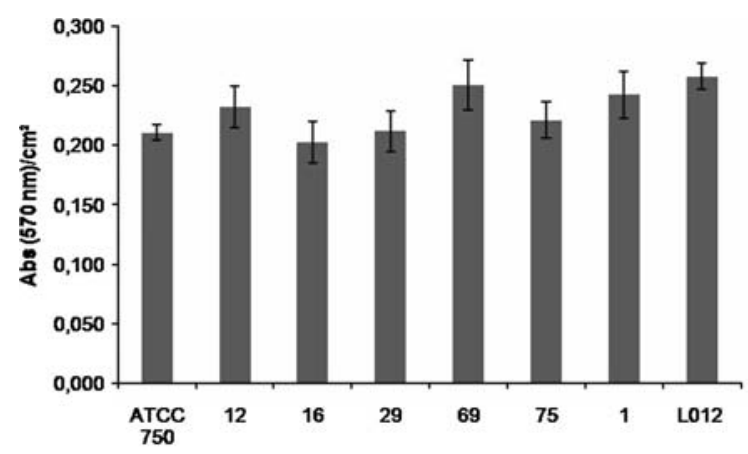

Fig. 2 Biofilm biomass on silicone measured by crystal violet staining, expressed as absorbance $(570 \mathrm{~nm}) / \mathrm{cm}^{2}$ [Abs $\left.(570 \mathrm{~nm}) / \mathrm{cm}^{2}\right]$. Mean \pm standard deviation 
Table 1 Comparison of putative virulence factors of C. tropicalis from clinical isolate, including proteolytic (Pro), phospholytic (Phos) and hemolysis (Hemo) activity and ability for pseudohyphae formation

\begin{tabular}{|c|c|c|c|c|c|}
\hline \multicolumn{2}{|c|}{ Isolates } & \multicolumn{3}{|c|}{ Activity } & \multirow{2}{*}{$\begin{array}{l}\text { Pseudohyphae } \\
\text { formation } \\
\%\end{array}$} \\
\hline Sites & Strain & $\mathrm{Pro}^{\mathrm{a}}$ & $\mathrm{Phos}^{\mathrm{a}}$ & Hemo & \\
\hline Urine & 12 & 1.00 & 1.00 & Total & 10 \\
\hline Urine & 16 & 0.81 & 1.00 & Total & 4 \\
\hline Urine & 29 & 0.85 & 1.00 & Total & 3 \\
\hline Urine & 75 & 1.00 & 1.00 & Total & 4 \\
\hline Urine & 69 & 1.00 & 1.00 & Total & 1 \\
\hline $\mathrm{CVC}$ & L012 & 0.89 & 0.66 & Total & 7 \\
\hline Blood & 1 & 0.69 & 1.00 & Total & 2 \\
\hline
\end{tabular}

a Values of enzyme activity, according to Price et al. [20]: $\mathrm{Pz}=1.00$ means that the test strain is negative for enzymtic activity, while a value of $\mathrm{Pz}<1.00$ means that the test strain is positive for enzyme activity

Concerning C. tropicalis pseudohyphae formation and enzymatic activity (Table 1), it was possible to verify that all isolates produced a low percentage of pseudohyphae formation. Among all, isolates 12 and L012 presented the highest production of pseudohyphae formation (10 and 7\%, respectively). Nevertheless, all isolates were able to express total hemolytic activity on sheep-blood agar medium supplemented with glucose. However, protease was only produced by two isolates from urine and by the isolates from catheter and blood and only one C. tropicalis (from CVC) was phospholipase positive.

The levels of $C$. tropicalis isolates antifungal susceptibility are shown in Table 2 . It is possible to observe that all isolates showed susceptibility (S) to VO, FLU and AMB. The largest percent of S-DD was observed for ITR in four strains and one clinical isolate from urine was found to be resistant (MIC $=1 \mu \mathrm{g} / \mathrm{ml}$ ).

\section{Discussion}

Nosocomial infections by Non-Candida albicans Candida (NCAC) species such as candidemia and candiduria have emerged as an increasing problem during the last two decades [22, 23]. Moreover, C. tropicalis appears to display higher potential for dissemination and mortality and possesses several virulence factors that can enhance the progression of infections than $C$. albicans and other NCAC species $[6,8,24]$.

In the present study, the results of morphological and biochemical tests were in agreement with molecular identification. Morphological, serological, or biochemical tests have been used, along the years, for the identification of Candida species. However, misidentification has been reported specially in relation to $C$. tropicalis $[3,10]$. Recently, molecular-based techniques, which are simpler and more efficient than the conventional tests, have been adapted to the identification of pathogenic microorganisms. In particular, due to its speed, reproducibility, high sensitivity and specificity, PCR tests have been increasingly used in laboratories for identification of several fungal species [3, 10, 17].

Concerning adhesion ability, it was possible to verify that all $C$. tropicalis adhered in a significantly higher extent $(P<0.05)$ to epithelial cells than to silicone. Sohn et al. [25] compared the ability of C. albicans to adhere to the human colorectal carcinoma cell line Caco-2 and epidermoid vulvovaginal A431 cells and to polystyrene and reported that $C$. albicans adheres in high extent to polystyrene and both epithelia. According to Bendel and Hostetter [26], the extent of adhesion to the human epithelial cell line HeLa S3 did not differ between $C$. albicans and $C$. tropicalis despite both species having distinct
Table 2 In vitro susceptibility of C. tropicalis from clinical isolates for amphotericin B (AMB), voriconazole (VO), itraconazole (ITR) and fluconazole (FLU)

a MIC interpretative criteria was performed according to the CLSI M27-A3 [21]

\begin{tabular}{|c|c|c|c|c|c|}
\hline \multicolumn{2}{|c|}{ Isolates } & \multicolumn{4}{|c|}{ Susceptibility category $(\mathrm{MIC} \mu \mathrm{g} / \mathrm{ml})^{\mathrm{a}}$} \\
\hline Sites & Strain & $\mathrm{AMB}$ & $\mathrm{VO}$ & ITR & FLU \\
\hline Urine & 12 & $S(0.5)$ & $\mathrm{S}(0.032)$ & $S(0.064)$ & $S(0.5)$ \\
\hline Urine & 16 & $\mathrm{~S}(0.25)$ & $\mathrm{S}(0.032)$ & S-DD $(0.38)$ & $S(0.5)$ \\
\hline Urine & 29 & $\mathrm{~S}(0.38)$ & $\mathrm{S}(0.023)$ & SDD $(0.38)$ & $\mathrm{S}(0.5)$ \\
\hline Urine & 75 & $\mathrm{~S}(1)$ & $\mathrm{S}(0.064)$ & SDD $(0.5)$ & $S(0.125)$ \\
\hline Urine & 69 & $S(0.125)$ & $\mathrm{S}(0.125)$ & $\mathrm{R}(1)$ & $\mathrm{S}(2)$ \\
\hline CVC & L012 & $\mathrm{S}(0.003)$ & $\mathrm{S}(0.023)$ & SDD (0.25) & $\mathrm{S}(1)$ \\
\hline Blood & 1 & $\mathrm{~S}(0.047)$ & $\mathrm{S}(0.012)$ & $\mathrm{S}(0.032)$ & $S(0.25)$ \\
\hline
\end{tabular}


mechanisms for this process. Nevertheless, the present results clearly show differences in the adhesion ability among the different isolates and hence adhesion of $C$. tropicalis to biotic and abiotic surfaces is strain dependant. Different intra-species adherence ability was also reported by other authors for other Candida species [9, 27-29].

We did not find a clear relation between pseudohyphae formation and adhesion capability. Although C. tropicalis $\mathrm{L} 012$, from CVC, and strain 12, from urine, adhered in higher extent to epithelial cells presenting also more pseudohyphae formation, the strain 75 exhibited an intermediate pseudohyphae formation and high adhesion ability. On the other hand, clinical isolates 29 and 69, from urine cultures, adhered to epithelial cells and displayed pseudohyphae formation in a lower extent than the other strains. This evidences the current lack of knowledge concerning the adhesion mechanisms of NCAC species to epithelium, as well as about the factors affecting the adhesion process [18].

Adhesion of Candida spp. to hard materials or host cells has been considered as an early step in biofilm formation [30, 31]. Nevertheless, it is important to highlight that, although strains 69 and 12 adhered in small number than other yeasts to silicone (Fig. 1) they showed higher ability to form biofilms on this material (Fig. 2). This result is consistent with other studies $[14,32]$, reporting differences between adhesion and biofilm formation abilities on polysterene and poly(vinyl chloride) (PVC) surfaces under static conditions, which also suggest that adhesion and biofilm formation of $C$. tropicalis are two distinct phenomena.

All C. tropicalis strains tested were able to form biofilms on silicone, which has important clinical impact once biofilm-associated infections are difficult to treat, representing a source of reinfections [23, 33]. Previous works also reported that $C$. tropicalis can form extensive in vitro biofilms in PVC catheters [34] and polystyrene surfaces [33].

The infective ability of yeasts depends on specific virulence mechanisms that confer the ability to colonize host surfaces, to invade deeper host tissue or to evade host defences [8, 35, 36]. During the pathogenic process many virulence attributes may be involved including production of extracellular proteases and phospholipases, as well as hemolytic activity [10-14, 37, 38]. In this study, all isolates were able to express total hemolytic activity. Manns et al. [12] demonstrated that $C$. albicans produced hemolytic activity and Luo et al. [13] observed that NCAC species are capable of producing one or more types of hemolysins in vitro with differences among species. Moreover, they observed that $C$. tropicalis was able to produce complete hemolysis after $48 \mathrm{~h}$, corroborating the results obtained herein.

In the present case, only few isolates were protease and phospholipase positive, corroborating the results of other authors [10, 39]. In opposition, Kumar et al. [38] detected 100 and $72.9 \%$ of proteases and phospholipase producers, respectively, among Candida spp. isolated from pulmonary tuberculosis patients. According to these results, protease and phospholipase expression can vary according to Candida species, strain and the site of isolation. Furthermore, although the methods used to test the presence of these enzymes are simple and fast they are not excessively accurate, specially compared with molecular methods that can detect gene expression [24, 36].

Concerning antifungal susceptibility results, all isolates were susceptible to VO, FLU and AMB and for four strains were S-DD for ITR. However, one clinical isolate showed to be resistant to ITR. These results are comparable to those reported in the literature, with slight differences that were dependent on the underlying disease and the Candida species involved in the infection [10, 14, 40, 41].

Though some authors have already assessed some C. tropicalis virulence factors, this work gathers, for the first time, the most important ones: secretion of enzymes, pseudohyphae formation, adhesion (to epithelial cells and silicone), biofilm formation and antifungal susceptibility. Despite it was not possible to establish a relation among the virulence factors assayed, it is interesting to notice that the strain isolated from CVC (L012) presented higher levels of all these factors. Furthermore, all clinical isolates presented one or more virulence factors.

\section{References}

1. Lundstrom T, Sobel J. Nosocomial candiduria: a review. Clin Infect Dis. 2001;32:1602-7. doi:10.1086/320531.

2. Colombo AL, Nucci M, Park BJ, Nouér SA, ArthingtonSkaggs B, da Matta DA, et al. Epidemiology of candidemia in Brazil: a nationwide sentinel surveillance of candidemia 
in eleven medical centers. J Clin Microbiol. 2006;44:281623. doi:10.1128/JCM.00773-06.

3. Asmundsdottir LR, Erlendsdottir H, Haraldsson G, Guo H, $\mathrm{Xu}$ J, Gottfredsson M. Molecular epidemiology of candidemia: evidence of clusters of smoldering nosocomial infections. Clin Infect Dis. 2008;47:17-24. doi:10.1086/58 9298.

4. Kauffman CA, Vazquez JA, Sobel JD, Gallis HA, McKinsey DS, Karchmer AW, et al. Prospective multicenter surveillance study of funguria in hospitalized patients. Clin Infect Dis. 2000;30:14-8. doi:10.1086/313583.

5. Álvarez-Lerma F, Nolla-Salas J, León C, Palomar M, Jordá $\mathrm{R}$, Carrasco $\mathrm{N}$, et al. Candiduria in critically ill patients admitted to intensive care medical units. Intensive Care Med. 2003;29:1069-76. doi:10.1007/s00134-003-1807-y.

6. Nucci M, Colombo AL. Candidemia due to Candida tropicalis: clinical, epidemiologic, and microbiologic characteristics of 188 episodes occurring in tertiary care hospitals. Diagn Microbiol Infect Dis. 2007;58:77-82. doi: 10.1016/j.diagmicrobio.2006.11.009.

7. Rho J, Shin JH, Song JW, Park MR, Kee SJ, Jang SJ, et al. Molecular investigation of two consecutive nosocomial clusters of Candida tropicalis candiduria using pulsed-field gel electrophoresis. J Microbiol. 2004;42:80-6.

8. Krcmery V, Barnes AJ. Non-albicans Candida spp. causing fungaemia: pathogenicity and antifungal resistance. J Hosp Infect. 2002;50:243-60. doi:10.1053/jhin.2001.1151.

9. Okawa Y, Miyauchi M, Kobayashi H. Comparison of pathogenicity of various Candida tropicalis strains. Biol Pharm Bull. 2008;31:1507-10.

10. Furlaneto-Maia L, Specian A, Bizerra F, de Oliveira M, Furlaneto M. In vitro evaluation of putative virulence attributes of oral isolates of Candida spp. obtained from elderly healthy individuals. Mycopathologia. 2008;166: 209-17. doi:10.1007/s11046-008-9139-7.

11. Tamura NK, Negri MFN, Bonassoli LA, Svidzinski TIE. Fatores de virulência de Candida spp isoladas de cateteres venosos e mãos de servidores hospitalares. Rev Soc Bras Med Trop. 2007;40:91-3. doi:10.1590/S0037-86822007 000100021.

12. Manns JM, Mosser DM, Buckley HR. Production of a hemolytic factor by Candida albicans. Infect Immun. 1994;62:5154-6. doi:10.1590/S0037-86822009000200029.

13. Luo G, Samaranayake LP, Yau JYY. Candida species exhibit differential in vitro hemolytic activities. J Clin Microbiol. 2001;39:2971-4. doi:10.1128/JCM.39.8.29712974.2001.

14. Bizerra FC, Nakamura CV, de Poersch C, Estivalet Svidzinski TI, Borsato Quesada RM, Goldenberg S, et al. Characteristics of biofilm formation by Candida tropicalis and antifungal resistance. FEMS Yeast Res. 2008;8:44250. doi:10.1111/j.1567-1364.2007.00347.x.

15. Maki DG, Weise CE, Sarafin HW. A semiquantitative culture method for identifying intravenous-catheter-related infection. N Engl J Med. 1977;296:1305-9.

16. Kurtzman CP, Fell JW (1998) The yeasts, a taxonomics. 4th ed. Elsevier Science.

17. Kanbe T, Horii T, Arishima T, Ozeki M, Kikuchi A. PCRbased identification of pathogenic Candida species using primer mixes specific to Candida DNA topoisomerase II genes. Yeast. 2002;19:973-89. doi:10.1002/yea.892.
18. Henriques M, Azeredo J, Oliveira R. Candida species adhesion to oral epithelium: factors involved and experimental methodology used. Crit Rev Microbiol. 2006;32: 217-26. doi:10.1080/10408410601023524.

19. Rüchel R. Proteinases of pathogenic fungi. Mycoses. 1999;42:48-52.

20. Price M, Wilkinson I, Gentry L. Plate method for detection of phospholipase activity in Candida albicans. Sabouraudia. 1982;20:7-14.

21. Clinical and Laboratory Standards Institute (CLSI). Reference method for broth dilution antifungal susceptibility testing of yeasts; approved standard. 3rd edition (M27-A3). CLSI document M27-A3. Wayne, PA, USA: Clinical and Laboratory Standards Institute.

22. Lai C-C, Tan C-K, Huang Y-T, Shao P-L, Hsueh P-R. Current challenges in the management of invasive fungal infections. J Infect Chemother. 2008;14:77-85. doi:10.1007/s10156007-0595-7.

23. Schelenz S. Management of candidiasis in the intensive care unit. J Antimicrob Chemother. 2008;61:31-4. doi: 10.1093/jac/dkm430.

24. Zaugg C, Borg-von Zepelin M, Reichard U, Sanglard D, Monod M. Secreted aspartic proteinase family of Candida tropicalis. Infect Immun. 2001;69:405-12. doi:10.1128/ IAI.69.1.405-412.2001.

25. Sohn K, Senyürek I, Fertey J, Königsdorfer A, Joffroy C, Hauser N, et al. An in vitro assay to study the transcriptional response during adherence of Candida albicans to different human epithelia. FEMS Yeast Res. 2006;6:108593. doi:10.1111/j.1567-1364.2006.00130.x.

26. Bendel C, Hostetter M. Distinct mechanisms of epithelial adhesion for Candida albicans and Candida tropicalis. Identification of the participating ligands and development of inhibitory peptides. J Clin Invest. 1993;92:1840-9. doi: 10.1172/JCI116775.

27. Panagoda GJ, Ellepola ANB, Samaranayake LP. Adhesion of Candida parapsilosis to epithelial and acrylic surfaces correlates with cell surface hydrophobicity. Mycoses. 2001;44:29-35. doi:10.1046/j.1439-0507.2001.00611.x.

28. Lyon PJ, Resende MA. Correlation between adhesion, enzyme production, and susceptibility to fluconazole in Candida albicans obtained from denture wearers. Oral Surg Oral Med Oral Pathol Oral Radiol Endod. 2006;102: 632-8. doi:10.1016/j.tripleo.2005.12.015.

29. Henriques M, Azeredo J, Oliveira R. The involvement of physico-chemical interactions in the adhesion of Candida albicans and Candida dubliniensis to epithelial cells. Mycoses. 2007;50:391-6. doi:10.1111/j.1439-0507.2007.01387.x.

30. Chandra J, Kuhn DM, Mukherjee PK, Hoyer LL, McCormick T, Ghannoum MA. Biofilm formation by the fungal pathogen Candida albicans: development, architecture, and drug resistance. J Bacteriol. 2001;183:5385-94. doi: 10.1128/JB.183.18.5385-5394.2001.

31. Douglas LJ. Candida biofilms and their role in infection. Trends Microbiol. 2003;11:30-6. doi:10.1016/S0966-842X (02)00002-1.

32. Silva S, Henriques M, Martins A, Oliveira R, Williams D, Azeredo J. Biofilms of non-Candida albicans Candida species: quantification, structure and matrix composition. Med Mycol. 2009;20:1-9. doi:10.1080/136937808025 49594. 
33. Shin JH, Kee SJ, Shin MG, Kim SH, Shin DH, Lee SK, et al. Biofilm production by isolates of Candida species recovered from nonneutropenic patients: comparison of bloodstream isolates with isolates from other sources. J Clin Microbiol. 2002;40:1244-8. doi:10.1128/JCM.40.4. 1244-1248.2002.

34. Hawser SP, Douglas LJ. Biofilm formation by Candida species on the surface of catheter materials in vitro. Infect Immun. 1994;62:915-21.

35. Yang Y. Virulence factors of Candida species. J Microbiol Immunol Infect. 2003;36:223-8.

36. Fu Y, Luo G, Spellberg BJ, Edwards JE Jr, Ibrahim AS. Gene overexpression/suppression analysis of candidate virulence factors of Candida albicans. Eukaryot Cell. 2008;7:483-92. doi:10.1128/EC.00445-07.

37. da Costa K, Ferreira J, Komesu M, Candido R. Candida albicans and Candida tropicalis in oral candidosis: quantitative analysis, exoenzyme activity, and antifungal drug sensitivity. Mycopathologia. 2009;167:73-9. doi:10.1007/ s11046-008-9154-8.
38. Kumar VG, Latha R, Vedhagiri K, Sathiamoorthi T, Jayarani G, Sasikala R, et al. Phospholipase C, proteinase and hemolytic activities of Candida spp. isolated from pulmonary tuberculosis patients. J Mycol Med. 2009;19: 3-10. doi:10.1016/j.mycmed.2008.11.002.

39. Gokce G, Cerikcioglu N, Yagci A. Acid proteinase, phospholipase, and biofilm production of Candida species isolated from blood cultures. Mycopathologia. 2007;164: 265-9. doi:10.1007/s11046-007-9053-4.

40. Johnson E, Espinel-Ingroff A, Szekely A, Hockey H, Troke P. Activity of voriconazole, itraconazole, fluconazole and amphotericin B in vitro against 1763 yeasts from 472 patients in the voriconazole phase III clinical studies. Int J Antimicrob Agents. 2008;32:511-4. doi:10.1016/j.ijanti micag.2008.05.023.

41. Panizo MM, Reviákina V, Dolande M, Selgrad S. Candida spp. in vitro susceptibility profile to four antifungal agents. Resistance surveillance study in Venezuelan strains. Med Mycol. 2009;47:137-43. doi:10.1080/13693780802144339 